Brit. F. vener. Dis. (1970) 46, 502

\title{
Sexually transmitted diseases
}

\section{Extract from the Annual Report of the Chief Medical Officer of the Department of Health and Social Security for the year 1969}

The control of the venereal diseases (syphilis, gonorrhoea, and chancroid) and of other sexually transmitted diseases continues to pose a major public health problem. Although, in general, syphilis remains controlled in Britain, a considerable number of new infectious cases are still seen in the clinics, and there is good reason to believe that a further appreciable number who attend elsewhere remain undiagnosed. Gonorrhoea still shows no sign of being checked and the further marked rise over the 1968 figures brings the total cases above the previous 'peak' level of 1946. The number of cases of some of the other sexually transmitted diseases has also increased. In particular there is no check in the regular year by year rise (since 1951) of non-gonococcal urethritis in the male, which is undoubtedly helped by the difficulties in the diagnosis of the equivalent infection in the female. Improved health education in the community probably explains why many more people now attend clinics for a check up following exposure but are found to have no evidence of infection. All these patients have to be examined, tested, put under surveillance and, finally, reassured.

In general, as a result of the further expansion of work in 1969, the clinics are now having to deal with almost double the number of new cases as compared with 10 years previously. There has been comparatively little increase in medical, nursing, and ancillary staff during this period, whereas new diagnostic techniques and improved social services have con-

'On the State of the Public Health'. Report of the Department of Health and Social Security for the year ended December 31, 1969, p. 57, and Appendix C, p. 236. H.M.S.O., London siderably increased the work load per patient. There are also in many clinics the urgent problems of space and of facilities; these have been greatly overloaded by the ever increasing numbers of new patients, particularly in the female section of clinics, where the increase has been proportionately greater.

\section{Syphilis}

The definition of early syphilis includes the primary, secondary and early latent stages. In 1968 in England there were 1,762 of these cases reported of which 1,393 were in males and 369 in females, an increase of 6.2 per cent. as compared with 1967 and giving a male/female ratio of $3 \cdot 8: 1$. The corresponding total for 1969 was 1,618 cases of which 1,314 were in males and 304 in females, a decrease of 8.2 per cent. as compared with 1968 and giving a male/female ratio of $4 \cdot 3: 1$. A different definition of infectious syphilis, which limits the group to those in the primary and secondary stages only, gives totals of 1,261 cases in 1968, of which 1,037 were in men and 224 in women, and 1,199 in 1969, of which 994 were in men and 205 in women, indicating a small improvement over 1968 and a male-female ratio of $4.8: 1$ as compared with $4 \cdot 6: 1$ in 1968.

The fact that the figures are decreasing is welcome, but the decrease is too small to give real satisfaction and it is essential that every effort should continue to bring this serious disease under better control.

The number of cases of primary, secondary, and early latent syphilis reported from ten urban areas in 1968 and 1969 are shown in Table $I$.

TA BLE I Early syphilitic infections dealt with for the first time in ten sample areas, 1968-69

\begin{tabular}{|c|c|c|c|c|c|c|c|}
\hline \multicolumn{2}{|l|}{ Year } & \multicolumn{3}{|l|}{1969} & \multicolumn{3}{|l|}{1968} \\
\hline Sex & & Male & Female & Total & Male & Female & Total \\
\hline $\begin{array}{l}\star \text { Inner London } \\
\text { Merseyside (Liverpool, Bootle, Wallasey and Birkenhead) } \\
\text { Manchester and Salford } \\
\text { Tyneside (Newcastle, South Shields and Tynemouth) } \\
\text { Hull, Kingston-upon-Humber } \\
\text { Southampton } \\
\text { Bristol } \\
\text { Birmingham } \\
\text { Leeds and Bradford } \\
\text { Sheffield }\end{array}$ & $\begin{array}{r}(2,981,580) \\
(1,000,710) \\
(731,520) \\
(418,880) \\
(292,600) \\
(210,000) \\
(427,230) \\
(1,086,400) \\
(796,930) \\
(528,860)\end{array}$ & $\begin{array}{r}732 \\
61 \\
36 \\
12 \\
19 \\
28 \\
16 \\
18 \\
18 \\
3\end{array}$ & $\begin{array}{r}118 \\
22 \\
11 \\
2 \\
15 \\
7 \\
4 \\
5 \\
8 \\
2\end{array}$ & $\begin{array}{r}850 \\
83 \\
47 \\
14 \\
34 \\
35 \\
20 \\
23 \\
26 \\
5\end{array}$ & $\begin{array}{r}778 \\
76 \\
42 \\
13 \\
20 \\
28 \\
33 \\
26 \\
13 \\
1\end{array}$ & $\begin{array}{r}149 \\
43 \\
9 \\
5 \\
15 \\
4 \\
1 \\
6 \\
3 \\
-\end{array}$ & $\begin{array}{r}927 \\
119 \\
51 \\
18 \\
35 \\
32 \\
34 \\
32 \\
16 \\
1\end{array}$ \\
\hline
\end{tabular}

«The inner London boroughs and City of London 
Cases from the inner London area, always the major source of infection, decreased from 927 in 1968 to 850 in 1969, that is nearly half the early infections in England. Both sexes showed appreciable decreases. There was a similar trend on Merseyside, and also at Bristol and Birmingham. Slight reductions were recorded at Manchester and Salford, Tyneside, and Hull. On the other hand increases occurred at Southampton, Leeds and Bradford, and Sheffield.

Table II indicates the number of cases in which syphilis, seen in the primary and secondary stages, was believed to have been contracted in England or abroad. The proportions were again similar to those of the previous year, $17 \cdot 1$ per cent. contracted abroad as compared with 15.8 per cent. in 1968 . The trend during the last 2 years has been slightly upward; physicians should continue to make every effort to pass on contact information to the Department so that steps can be taken to inform the appropriate medical authorities in the countries of residence of the contacts.

T A B LE I I Infections contracted at home and abroad, 1969

\begin{tabular}{|c|c|c|c|c|}
\hline \multirow{2}{*}{ Infection } & \multicolumn{2}{|l|}{ Syphilis } & \multicolumn{2}{|c|}{ Gonorrhoea } \\
\hline & Number & Per cent. & Number & Per cent \\
\hline Contracted in England & 939 & $78 \cdot 3$ & 47,013 & $94 \cdot 2$ \\
\hline Contracted abroad & 205 & $17 \cdot 1$ & 1,858 & 3.7 \\
\hline Not known & 55 & $4 \cdot 6$ & 1,039 & $2 \cdot 1$ \\
\hline
\end{tabular}

Information obtained from the clinics in England on the ages of patients with primary and secondary syphilis is shown in Table VI (below). It relates to 1,187 patients who contributed a total of 1,199 infections. Of 986 males, 79 (8 per cent.) were under the age of 20 years, and of 201 females, 61 (30.3 per cent.) were also in that age group. The equivalent percentages for 1968 were 6.8 and 21.0 respectively.

The Co-operative Clinical Group of the Medical Society for the Study of Venereal Diseases has continued its yearly assessment of the relative incidence of primary and secondary syphilis among those born in the United Kingdom and those born elsewhere. Details were obtained from 181 clinics in England and Wales relating to 1,225 cases, of which 994 were in men and 231 in women, comprising 96.8 per cent. of the total officially reported cases. Of the men, $66 \cdot 1$ per cent. were born in the United Kingdom (as compared with 65.0 per cent. in 1968), 8.5 per cent. in the West Indies, 7.4 per cent. in the Continent of Europe, 4.6 per cent. in Asia, and 4.3 per cent. in Eire; smaller numbers came from other countries. Of the women, 73.6 per cent. were born in the United
Kingdom (as compared with 79.7 per cent. in 1968), 10.8 per cent. in the West Indies, 7.3 per cent. in Eire, and 4.3 per cent. on the Continent of Europe; smaller numbers were born in other countries. As the years pass an increasing proportion of those born abroad are resident here and are not recent immigrants. Some, however, are short-stay visitors, or foreign seamen, who are provided with free treatment under the Brussels Agreement.

During 1969 it was possible to take action regarding the contacts of 845 of the 994 cases in males suffering from primary or secondary syphilis and of 139 of the 205 cases in women. As a result of these measures, 117 infected male contacts and 90 infected female contacts were brought under treatment, as compared with 101 men and 103 women in 1968. This continued increase in total numbers is satisfactory and reflects the laudable efforts of social workers who have undertaken the necessary field work to bring these 207 patients to the clinics for diagnosis and treatment. This must have contributed substantially to the control of the disease.

Cases of late syphilis decreased to 1,420 in 1969 in England as compared with 1,613 in 1968. These details are shown in Table III. These figures are further evidence that syphilis has been held in check, although it is true that the widespread use for other diseases of antibiotics with a treponemicidal effect may have had an influence. All patients with clinically latent syphilis should have routine examination of the cerebrospinal fluid and $x$ rays of the aorta to exclude asymptomatic neurosyphilis or aortitis. Patients with clinical late syphilis are now so seldom seen that the present generation of students in medical schools can have little experience of them.

T A B LE I I L Late syphilis-England, 1968-69

\begin{tabular}{|c|c|c|c|c|}
\hline Type of late syphilis & Year & Males & Females & Total \\
\hline Cardiovascular syphilis & $\begin{array}{l}1968 \\
1969\end{array}$ & $\begin{array}{l}81 \\
89\end{array}$ & $\begin{array}{l}44 \\
32\end{array}$ & $\begin{array}{l}125 \\
121\end{array}$ \\
\hline Neurosyphilis & $\begin{array}{l}1968 \\
1969\end{array}$ & $\begin{array}{l}144 \\
124\end{array}$ & $\begin{array}{l}71 \\
46\end{array}$ & $\begin{array}{l}215 \\
170\end{array}$ \\
\hline All other late or latent stages & $\begin{array}{l}1968 \\
1969\end{array}$ & $\begin{array}{l}721 \\
628\end{array}$ & $\begin{array}{l}552 \\
501\end{array}$ & $\begin{array}{l}1,273 \\
1,129\end{array}$ \\
\hline Totals. Late or Latent Stages & $\begin{array}{l}1968 \\
1969\end{array}$ & $\begin{array}{l}946 \\
841\end{array}$ & $\begin{array}{l}667 \\
579\end{array}$ & $\begin{array}{l}1,613 \\
1,420\end{array}$ \\
\hline
\end{tabular}

The fall in numbers of new immigrants probably accounts for the diminished number of new cases of other treponemal diseases, such as yaws, seen in the clinics in England. In 1968 it was noted that positive serological tests thought to be due to the non-venereal treponematoses were found in 953 cases. The equivalent figure for 1969 was 837 which was even lower than the 1967 figure of 898 . 
Figures from the Registrar General's Annual Statistical Review show year by year the number of deaths assigned to the most serious forms of clinical late syphilis. Figures are given in Appendix Table D.

The situation with congenital syphilis shows little change; this is not a major problem. However, a few new cases in neonates continue to be reported and careful examination, including blood testing, of all pregnant women remains essential. Cases diagnosed in England in infants in the first year of life amounted to 16 in 1969 compared with 14 in 1968 (Appendix Table C).

The results of blood tests for syphilis in those groups of the population to which these tests are regularly applied, such as pregnant women, give an estimate of the prevalence of latent undiagnosed treponemal disease. Table IV shows the results of tests reported in 1969 from regional blood transfusion centres at which routine tests are performed for the regions concerned.

Table IV shows that the proportion of these patients with positive tests remains very low and Table V, which summarizes the results at these centres during the past 15 years, shows that the incidence has declined consistently during the last 7

T A B LE $\mathrm{V}$ Results of syphilis tests at regional centres, 1954-69

\begin{tabular}{|c|c|c|c|c|}
\hline \multirow{2}{*}{ Year } & \multicolumn{2}{|c|}{ Primiparae } & \multicolumn{2}{|c|}{ Multiparae } \\
\hline & No. & Per cent. positive & No. & Per cent. positive \\
\hline 1954 & 39,181 & 0.23 & 47,941 & 0.32 \\
\hline 1955 & 41,392 & 0.21 & 40,712 & 0.43 \\
\hline 1956 & 48,420 & 0.28 & 40,295 & 0.35 \\
\hline 1957 & 49,914 & 0.14 & 43,730 & 0.29 \\
\hline 1958 & 49,315 & 0.13 & 40,765 & 0.23 \\
\hline 1959 & 56,962 & 0.14 & 46,531 & 0.16 \\
\hline 1960 & 61,606 & 0.08 & 46,349 & 0.14 \\
\hline 1961 & 67,294 & 0.13 & 49,583 & 0.27 \\
\hline 1962 & 61,872 & 0.11 & 48,433 & 0.19 \\
\hline 1963 & 68,347 & $0 \cdot 16$ & 57,774 & 0.22 \\
\hline 1964 & 69,412 & 0.12 & 61,362 & 0.20 \\
\hline 1965 & 72,623 & $0 \cdot 10$ & 61,287 & 0.13 \\
\hline 1966 & 69,662 & 0.07 & 59,043 & 0.11 \\
\hline 1967 & 70,859 & 0.05 & 58,782 & 0.08 \\
\hline 1968 & 72,931 & 0.05 & 65,744 & 0.06 \\
\hline 1969 & 75,253 & 0.07 & 68,647 & $0 \cdot 10$ \\
\hline
\end{tabular}

years. The one centre which seems materially out of line is Plymouth, as was shown in 1968.

\section{Gonorrhoea}

The further increase of cases in 1969 brings the total figure above the previous peak of 1946. Recent reports from many other countries, including the United States of America, show that the situation is as bad or worse there. In England it is probable that the majority of patients with gonorrhoea attend the clinics, thus giving the contact tracers the best opportunity of bringing in symptomless female contacts. The number of cases of gonorrhoea in England in 1968 was 43,922 , an increase of $7 \cdot 1$ per cent. over 1967 (which had shown an increase of 11.6 per cent. over the 1966 figures). In 1969 there has been a further increase to 50,037, no less than 13.9 per cent. above last year. Cases in adult males rose from 31,829 in 1968 to 35,505 in 1969; those in adult females from 12,006 to 14,405 . The male/female ratio was approximately $2 \cdot 5: 1$ as compared with $2 \cdot 7: 1$ in 1968. This continual small reduction in the ratio may mean that a larger proportion of infected women has been brought into the clinics, possibly by the social workers in many areas. Physicians in charge of clinics in which the male/female ratio is appreciably higher than the national average should consider whether they are making full use of the newer contact tracing methods. The total of 50,037 cases includes 82 of vulvo-vaginitis, as compared with 54 in 1968, and 45 of gonococcal ophthalmia of the newborn as compared with 33 in 1968. The statistics from the clinics showed that 49,910 infections acquired by patients from the age of puberty involved 45,056 individual patients, indicating the large number with more than one infection attending the same clinic in the same year.

The ages of patients suffering from gonorrhoea in England are shown in Table VI. The proportion of patients with gonorrhoea under the age of 20 was 17.0 per cent. as compared with 15.6 per cent. in 1968. There were 72 boys and 331 girls under the age of 16 who presented with infection as compared with

T A BLE IV Syphilis in pregnancy, 1969

\begin{tabular}{|c|c|c|c|c|c|c|c|c|c|}
\hline \multirow{3}{*}{ Centre } & \multicolumn{3}{|c|}{ No. of ante-natal patients } & \multicolumn{6}{|c|}{ Positive syphilis tests } \\
\hline & \multirow[t]{2}{*}{ Primiparae } & \multirow[t]{2}{*}{ Multiparae } & \multirow[t]{2}{*}{ Parity not known } & \multicolumn{2}{|c|}{ Primiparae } & \multicolumn{2}{|c|}{ Multiparae } & \multicolumn{2}{|c|}{ Parity not known } \\
\hline & & & & No. & Per cent. & No. & Per cent. & No. & Per cent. \\
\hline Cambridge & 10,703 & 13,270 & 784 & 17 & $0 \cdot 16$ & 29 & 0.22 & - & - \\
\hline Leeds & 12,264 & 7,499 & 1,631 & 15 & 0.12 & 13 & 0.17 & 1 & 0.06 \\
\hline Liverpool & 20,783 & 25,927 & - & 5 & 0.02 & 8 & 0.03 & - & - \\
\hline Oxford & 4,960 & 4,927 & 660 & 2 & 0.04 & 2 & 0.03 & 0 & 0 \\
\hline Plymouth & 2,412 & 2,596 & - & 6 & $0 \cdot 25$ & 11 & 0.42 & - & - \\
\hline Sheffield & 24,131 & 14,428 & - & 6 & 0.02 & 4 & 0.03 & - & - \\
\hline
\end{tabular}


T A B L E V I Ages of patients suffering from early syphilis and gonorrhoea, England, 1969

\begin{tabular}{|c|c|c|c|c|c|c|c|c|}
\hline \multirow{2}{*}{ Age (yrs) } & \multicolumn{4}{|c|}{ Primary and secondary syphilis } & \multicolumn{4}{|c|}{ Gonorrhoea } \\
\hline & Males & Females & Total No. & Percent. & Males & Females & Total No. & Per cent. \\
\hline $\begin{array}{l}\text { Under } 16 \\
16-17 \\
18-19 \\
20-24 \\
25 \text { and over }\end{array}$ & $\begin{array}{r}2 \\
18 \\
59 \\
256 \\
651\end{array}$ & $\begin{array}{r}3 \\
19 \\
39 \\
55 \\
85\end{array}$ & $\begin{array}{r}5 \\
37 \\
98 \\
311 \\
736\end{array}$ & $\begin{array}{r}0 \cdot 4 \\
3 \cdot 1 \\
8 \cdot 3 \\
26 \cdot 2 \\
62 \cdot 0\end{array}$ & $\begin{array}{r}72 \\
732 \\
2,754 \\
10,006 \\
18,267\end{array}$ & $\begin{array}{r}331 \\
1,365 \\
2,427 \\
4,692 \\
4,410\end{array}$ & $\begin{array}{r}403 \\
2,097 \\
5,181 \\
14,698 \\
22,677\end{array}$ & $\begin{array}{r}0.9 \\
4.7 \\
11.5 \\
32.6 \\
50.3\end{array}$ \\
\hline Totals & 986 & 201 & 1,187 & $100 \cdot 0$ & 31,831 & 13,225 & 45,056 & $100 \cdot 0$ \\
\hline
\end{tabular}

69 boys and 215 girls in 1968 . The number of boys aged 16 to 19 was 3,486 compared with 2,854 in 1968 and the number of girls was 3,792 as compared with 3,054 in 1968. In the age groups of 19 years and under, the total for boys at 3,558 was outnumbered by the girls at 4,123 .

Over the last few years there has been a gradual increase in the proportion of patients in these younger age groups, and, as some are still at school, this must give rise to concern. This year's increase over 1968 was no less than 24.0 per cent. in the age group under 20 compared with the overall increase of 13.9 per cent.

The Co-operative Clinical Group conducted a further study into the countries of origin of patients suffering from gonorrhoea. Details were collected from 181 clinics in England and Wales relating to 49,445 cases, or 96.5 per cent. of the total officially reported in the Annual Returns. Of 34,884 men suffering from gonorrhoea, 58.3 per cent. were born in the United Kingdom, as compared with 57.8 per cent. in a similar study in $1968 ; 18.5$ per cent. were born in the West Indies, $5 \cdot 1$ per cent. in Asia, 4.8 per cent. in Eire, 4.2 per cent. on the Continent of Europe, and 4.0 per cent. in Mediterranean countries; smaller numbers came from elsewhere. Of 14,561 females, 81.5 per cent. were born in the United Kingdom (as compared with 82.7 per cent. in 1968), 7.6 per cent. in the West Indies, 7.3 per cent. in Eire, 4.3 per cent. on the Continent of Europe, with smaller numbers from other countries.

During 1969 it was possible to take action regarding the contacts of 26,701 patients suffering from gonorrhoea, of whom 23,320 were men and 3,381 were women. As the result of these measures the attendance was secured of 8,443 infected contacts, of whom 1,541 were men and 6,902 were women. These figures compare with 1,377 men and 5,618 women in 1968. This indicates the increased volume of work carried out by the contact-tracing social workers.

\section{Chancroid}

The disease is becoming relatively rare in the United Kingdom, but 56 cases were seen in England in 1969 compared with 52 in 1968.

\section{Prostitutes in Holloway Prison}

The number of prostitutes admitted to H.M. Prison, Holloway, during 1969 was 506 as compared with 495 in 1968. The total number of admissions numbered 756 in 1969, as compared with 749 in 1968. No tests were taken on 33 admissions, for various reasons. Tests were refused on 102 admissions involving 48 prostitutes ( 60 of these refusals were by six individuals). A diagnosis of early syphilis was made in four patients (one primary, one secondary, and two latent); none was under the age of 20 years. A diagnosis of gonorrhoea was made in 62 cases involving 61 patients; of these 21 were under the age of 20 years.

\section{Other sexually transmitted diseases}

Non-gonococcal genital infection

The aetiology of this condition remains uncertain, but recent advances in research suggest that the 'TRIC agent' of the Chlamydia group may be the infective agent in a high proportion of cases. Since a clinical diagnosis is possible in the male, cases have been recorded for males since 1951, when 10,794 cases were reported in England and Wales. In 1969 in England the number was 40,320 cases, as compared with 35,040 in 1968 . This infection is clearly not controlled, and one of the main reasons is the difficulty in making a clinical diagnosis in women. In most clinics, however, an attempt is made and the patient receives empirical treatment in the hope of preventing the re-infection of male patients. The cases in females are reported under the category 'other conditions requiring treatment', for which figures in England have risen in women from 32,729 in 1968 to 39,581 in 1969.

\section{Trichomoniasis}

This condition is generally considered to be usually sexually transmitted and is commonly associated with gonorrhoea in females. The number of cases diagnosed in the clinics in England and Wales has been reported in the quarterly returns since 1967. In 1969 in England there were 13,596 cases, of which 1,001 occurred in males and 12,595 in females, as compared 
with a total in England of 11,837 in 1968 (975 males, 10,862 females). In the annual returns these cases are still included under 'other conditions requiring treatment'.

\section{Lymphogranuloma venereum and granuloma inguinale} These diseases are more usually seen in recent immigrants. In 1969 there were 34 cases of lymphogranuloma venereum and 3 of granuloma inguinale, as compared with 55 cases and 11 cases respectively in 1968. Both these conditions can, if neglected, give rise to local malignant changes.

\section{Other conditions}

These include pediculosis pubis, genital scabies, genital warts, genital herpes, and genital molluscum contagiosum. The presence of these conditions should always indicate to a doctor the possibility of more serious venereal diseases for which tests should always be carried out in order to exclude them. Genital candidiasis can also be sexually transmitted once it has been established in one sex partner as a result of pregnancy (or possibly of the contraceptive pill) in women, and in either sex of diabetes or of therapy with broad spectrum antibiotics or immunosuppressive drugs. These diseases, when seen at the clinics, are still included under 'other conditions requiring treatment'; this category totalled 71,073 cases in 1969 as compared with 59,628 cases in 1968.

Cases $(a)$ with other genital conditions not usually sexually transmitted, and $(b)$ in which no disease is found (although a sex risk may have been taken), are usually included under the heading 'conditions requiring no treatment', although some of group (a) may be included with cases in the previous paragraph if treatment is needed in the clinic, or if they have been referred to another department. The number of cases requiring no treatment numbered 56,741 in 1969 , as compared with 48,174 in 1968 .

\section{The present position}

The sexually transmitted diseases are on the increase and appear to be widespread throughout the community, although there seems to be an incidence above average in immigrants and homosexuals, and the younger age groups are more commonly affected than those over 30. Infection is least likely if there is a single constant and established sexual partnership based on an emotional relationship, whether or not within marriage. Education of the next generation should bring to the individual boy or girl an understanding of the importance of personal relationships with others. The Health Education Council has recently analysed the reactions of both children and parents to the showing of the American film on venereal diseases 'Quarter of a Million Teenagers' which met with a satisfactory response from both groups. There is a need for a British film on this subject. The Council is also preparing new posters for display in youth clubs and other places where the young foregather as well as a film strip additional to the two already available. Some venereologists believe that the ultimate step in control could be immunization of the community against the various sexually transmitted diseases. To be effective this would have to be undertaken in some as early as the age of puberty, and in itself would pose many social and psychological problems for both parents and children. While some progress in research on immunization has been made in relation to syphilis in the United States, research has scarcely started on this aspect of gonorrhoea. The aetiology of nongonococcal infections still remains obscure, and so, for them, problems of immunization cannot yet be considered. However, it is encouraging for future research in Britain that the Medical Research Council recently convened a one-day conference on 'current problems of urethritis' which brought together clinicians and research workers to discuss basic problems of epidemiological and laboratory research, and it is to be hoped that the Council will be able to support such research projects if and when submitted.

When methods of prevention fail in the community, it is essential that individuals know where they can seek help, and it is the duty of all local health authorities to ensure that this information is readily available through notices, by posters, or by newer methods of information such as that (spoken or recorded) obtained by dialling an advertised telephone number. Some general practitioners may be prepared to treat such of their registered patients as have sexually transmitted diseases, if the diagnostic facilities and aid in the tracing of all sex contacts are provided, but if this is not possible then these patients are best referred rapidly to the nearest clinic for diagnosis before any treatment has been given. Physicians in charge of clinics should inform themselves about newer diagnostic techniques and therapeutic advances and can achieve this by attending appropriate professional meetings. In the international field the World Health Organisation, through its Venereal Diseases and Treponematoses Division, is active in disseminating knowledge of recent advances in the subject and also in encouraging promoting, and supporting research projects.

During 1969 the pressure of rising numbers of new patients has made it increasingly difficult for clinic staff, often working in cramped and old premises, to keep up the high standards of patient care previously maintained. When a clinic's capacity is overloaded the 
result is a lower number of attendances per patient, reflecting inadequate post-treatment care and follow up, and also a higher male to female ratio of cases, due to inadequate tracing of asymptomatic female contacts. It may be possible to off-load cases from the clinics under the severest pressure by increasing the staff, clinic sessions, and capacity of surrounding clinics which may at present be working only part time. However, some physicians in charge will need to seek new enlarged and modernized clinics as part of hospital development in their areas. An increase in consultants will depend on the recruiting of adequately qualified senior registrars for training in the subject in suitably selected posts, while the provision of adequate supporting staff will depend on the training of sufficient numbers of general practitioners as part-time clinical assistants. This is encouraged by the Postgraduate Federation which organizes a course in Clinical Venereology in the London area that is available to general practitioners, who attend a major clinic for instruction for 22 3-hour sessions over a period of 3 to 6 months.
The newer contact-tracing methods for the venereal diseases recommended in December 1968, seem to have encouraged many local health authorities to appoint social workers to be seconded to the clinics. Provided there is co-operation by all the clinic doctors, additional patients who are known contacts of early syphilis, or of gonorrhoea, will undoubtedly continue to be brought to hospital for diagnosis and treatment. Many of these are irresponsible girls who, because of the absence of the symptoms, would not otherwise attend. It is hoped that the small number of doctors and local authorities who have had doubts concerning these methods will be convinced of their value during the coming year. The contact report forms were considered by some as liable to infringe the rights of the individual, but after further consultation it was agreed to modify them and reissue them in the near future.

It is only by employing these various methods of control with enthusiasm and efficiency that all concerned can hope to check the continuing increase in cases of sexually transmitted diseases in the United Kingdom.

\section{APPENDIX}

T A B L A Number of cases (in all stages) dealt with for the first time at any centre in England, 1965-69

\begin{tabular}{|c|c|c|c|c|c|c|c|c|}
\hline \multirow{2}{*}{$\operatorname{Sex}$} & \multirow{2}{*}{ Year } & \multirow{2}{*}{ Syphilis } & \multirow{2}{*}{$\begin{array}{l}\text { Soft } \\
\text { chancre }\end{array}$} & \multirow{2}{*}{ Gonorrhoea } & \multirow{2}{*}{$\begin{array}{l}\text { Non- } \\
\text { gonococcal } \\
\text { urethritis } \\
\text { (males only) }\end{array}$} & \multicolumn{2}{|c|}{ Other conditions } & \multirow[b]{2}{*}{$\begin{array}{l}\text { Total } \\
\text { cases }\end{array}$} \\
\hline & & & & & & $\begin{array}{l}\text { Requiring } \\
\text { treatment }\end{array}$ & $\begin{array}{l}\text { Not } \\
\text { requiring } \\
\text { treatment }\end{array}$ & \\
\hline Male & $\begin{array}{l}1965 \\
1966 \\
1967 \\
1968 \\
1969\end{array}$ & $\begin{array}{l}2,719 \\
2,374 \\
2,348 \\
2,433 \\
2,240\end{array}$ & $\begin{array}{l}60 \\
73 \\
55 \\
50 \\
53\end{array}$ & $\begin{array}{l}27,343 \\
27,437 \\
30,024 \\
31,838 \\
35,519\end{array}$ & $\begin{array}{l}28,587 \\
29,820 \\
31,884 \\
35,040 \\
40,320\end{array}$ & $\begin{array}{l}20,603 \\
21,811 \\
24,018 \\
26,899 \\
31,492\end{array}$ & $\begin{array}{l}29,498 \\
28,720 \\
28,051 \\
31,238 \\
36,477\end{array}$ & $\begin{array}{l}108,810 \\
110,235 \\
116,380 \\
127,498 \\
146,101\end{array}$ \\
\hline Female & $\begin{array}{l}1965 \\
1966 \\
1967 \\
1968 \\
1969\end{array}$ & $\begin{array}{l}1,210 \\
1,179 \\
1,125 \\
i, 179 \\
1,028\end{array}$ & $\begin{array}{l}5 \\
2 \\
1 \\
2 \\
3\end{array}$ & $\begin{array}{r}8,630 \\
9,421 \\
10,984 \\
12,084 \\
14,518\end{array}$ & $\begin{array}{c}- \\
- \\
-\end{array}$ & $\begin{array}{l}22,195 \\
24,540 \\
27,646 \\
32,729 \\
39,581\end{array}$ & $\begin{array}{l}14,175 \\
15,572 \\
15,582 \\
16,936 \\
20,264\end{array}$ & $\begin{array}{l}46,215 \\
50,714 \\
55,338 \\
62,930 \\
75,384\end{array}$ \\
\hline
\end{tabular}

^Excludes cases transferred from centre to centre

TA B LE B Cases of acquired syphilis in Table $A$ with infections of less than one year, England, 1965-69

\begin{tabular}{|c|c|c|c|c|}
\hline \multirow{2}{*}{ Year } & \multicolumn{2}{|c|}{ Number } & \multicolumn{2}{|c|}{ Percentage of Table $A$ cases } \\
\hline & Males & Females & Males & Females \\
\hline $\begin{array}{l}1965 \\
1966 \\
1967 \\
1968 \\
1969\end{array}$ & $\begin{array}{l}1,697 \\
1,396 \\
1,323 \\
1,393 \\
1,314\end{array}$ & $\begin{array}{l}371 \\
374 \\
335 \\
369 \\
304\end{array}$ & $\begin{array}{l}62 \cdot 4 \\
58 \cdot 8 \\
56 \cdot 3 \\
57 \cdot 2 \\
58 \cdot 7\end{array}$ & $\begin{array}{l}30.7 \\
31.6 \\
29 \cdot 8 \\
31 \cdot 3 \\
29.6\end{array}$ \\
\hline
\end{tabular}

TABLE C Cases of congenital syphilis dealt with for the first time at the treatment centres, England, 1965-69

\begin{tabular}{llllll}
\hline Year & Under 1 year & 1 and under 5 years & 5 and under 15 years & 15 years and over & Total \\
\cline { 2 - 7 } 1965 & 16 & 4 & 5 & 221 & 246 \\
1966 & 12 & 5 & 9 & 218 & 244 \\
1967 & 12 & - & 5 & 183 & 213 \\
1968 & 14 & 1 & 6 & 210 & 237 \\
1969 & 16 & 1 & 3 & 230 & \\
\hline
\end{tabular}


TABLE D Deaths from general paralysis of the insane, tabes dorsalis, and aneurysm of the aorta, England and Wales, 1967-69

\begin{tabular}{|c|c|c|c|c|c|c|}
\hline \multirow{2}{*}{ Year } & \multicolumn{2}{|l|}{ G.P.I. } & \multicolumn{2}{|c|}{ Tabes dorsalis } & \multicolumn{2}{|c|}{$\star$ Aneurysm of aorta } \\
\hline & Males & Females & Males & Females & Males & Females \\
\hline $\begin{array}{l}1967 \\
1968 \\
1969\end{array}$ & $\begin{array}{l}23 \\
16 \\
13\end{array}$ & $\begin{array}{r}4 \\
9 \\
11\end{array}$ & $\begin{array}{l}14 \\
14 \\
18\end{array}$ & $\begin{array}{r}12 \\
6 \\
10\end{array}$ & $\begin{array}{l}26 \\
15 \\
28\end{array}$ & $\begin{array}{l}45 \\
29 \\
24\end{array}$ \\
\hline
\end{tabular}

*Deaths from aneurysm of aorta specified as syphilitic only

T A B L E New cases of primary and secondary and early syphilis and post-pubertal gonorrhoea per 100,000 population, by age group and sex, Hospital Clinics, England and Wales, 1969

\begin{tabular}{|c|c|c|c|c|c|}
\hline \multirow{2}{*}{ Disease } & \multirow{2}{*}{ Age group (yrs) } & \multicolumn{4}{|l|}{ Sex } \\
\hline & & \multicolumn{2}{|l|}{ Male } & \multicolumn{2}{|l|}{ Female } \\
\hline Syphilis Early & All ages $\star$ & $5 \cdot 74$ & $(5 \cdot 86)$ & $1 \cdot 28$ & $(1 \cdot 28)$ \\
\hline Primary and secondary & $\begin{array}{l}\text { All ages } t \\
\text { Under } 16 \\
16 \text { and } 17 \\
18 \text { and } 19 \\
20-24 \\
25 \text { and over }\end{array}$ & $\begin{array}{r}4.39 \\
0.03 \\
3 \cdot 12 \\
8 \cdot 83 \\
14.32 \\
4 \cdot 82\end{array}$ & $(4 \cdot 43)$ & $\begin{array}{l}0.89 \\
0.05 \\
3.10 \\
5.84 \\
3.48 \\
0.59\end{array}$ & $(0 \cdot 87)$ \\
\hline Congenital & $\begin{array}{l}\text { All ages } t \\
\text { Under } 1 \text { year } \\
1-4 \\
5-14 \\
15 \text { and over }\end{array}$ & $\begin{array}{l}0.39 \\
1.70 \\
-\quad \\
\end{array}$ & $(0 \cdot 38)$ & $\begin{array}{l}0.67 \\
2.30 \\
0.06 \\
0.08 \\
0.80\end{array}$ & $(0.61)$ \\
\hline Gonorrhoea, post-pubertal & $\begin{array}{l}\text { All ages } t \\
\text { Under } 16 \\
16 \text { and } 17 \\
18 \text { and } 19 \\
20-24 \\
25 \text { and over }\end{array}$ & $\begin{array}{r}153 \cdot 10 \\
1 \cdot 33 \\
125 \cdot 74 \\
452 \cdot 39 \\
609 \cdot 09 \\
145 \cdot 73\end{array}$ & $(158 \cdot 34)$ & $\begin{array}{r}58.90 \\
5.93 \\
243.02 \\
400.26 \\
280.85 \\
30.46\end{array}$ & $(60 \cdot 86)$ \\
\hline
\end{tabular}

*Primary, secondary, and latent in the first year of infection tFigures in parentheses are for England only

T A B L E F New cases of other conditions per 100,000 population, all ages, by sex, England, 1969

Condition

(i) Chancroid

(ii) Lymphogranuloma venereum

(iii) Granuloma inguinale

(iv) Non-gonococcal urethritis

(v) Non-gonococcal urethritis with arthritis Total of (iv) and (v)

(vi) Late or latent treponematoses presumed to be non-syphilitic

(vii) Other conditions requiring treatment within the centre

(viii) Conditions requiring no treatment within the centre

(ix) Undiagnosed conditions

Total of lines (i) to (ix)

\begin{tabular}{|c|c|}
\hline Male & Female \\
\hline $\begin{array}{l}0.24 \\
0.13 \\
0.01\end{array}$ & $\begin{array}{r}0.01 \\
0.02 \\
-\quad\end{array}$ \\
\hline $\begin{array}{r}178.20 \\
1.61 \\
179.81\end{array}$ & 二 \\
\hline $2 \cdot 20$ & 1.45 \\
\hline $140 \cdot 44$ & $167 \cdot 16$ \\
\hline $\begin{array}{r}162.67 \\
0.40\end{array}$ & $\begin{array}{r}85.58 \\
0.74\end{array}$ \\
\hline $485 \cdot 90$ & 254.97 \\
\hline
\end{tabular}

